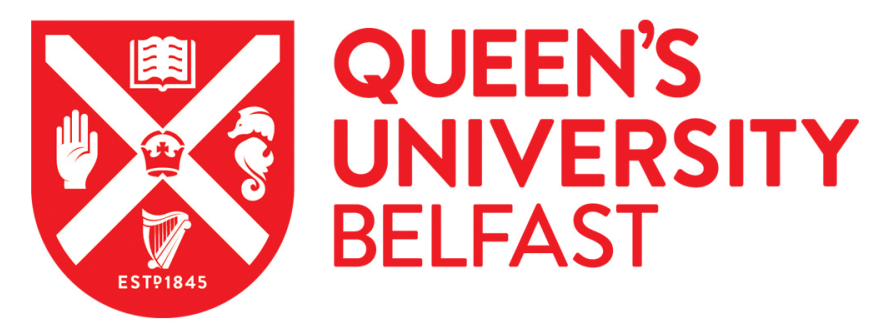

\title{
Modelling gold futures: should the level of speculation inform our choice of variables?
}

Coyle, C., Gogolin, F., \& Kearney, F. (2018). Modelling gold futures: should the level of speculation inform our choice of variables? European Journal of Finance, 25(10), 966-977.

https://doi.org/10.1080/1351847X.2018.1559212

\section{Published in:}

European Journal of Finance

\section{Document Version:}

Peer reviewed version

Queen's University Belfast - Research Portal:

Link to publication record in Queen's University Belfast Research Portal

Publisher rights

(C) 2018 Informa UK Limited, trading as Taylor \& Francis Group.

This work is made available online in accordance with the publisher's policies. Please refer to any applicable terms of use of the publisher.

\section{General rights}

Copyright for the publications made accessible via the Queen's University Belfast Research Portal is retained by the author(s) and / or other copyright owners and it is a condition of accessing these publications that users recognise and abide by the legal requirements associated with these rights.

Take down policy

The Research Portal is Queen's institutional repository that provides access to Queen's research output. Every effort has been made to ensure that content in the Research Portal does not infringe any person's rights, or applicable UK laws. If you discover content in the Research Portal that you believe breaches copyright or violates any law, please contact openaccess@qub.ac.uk. 


\title{
Modelling Gold Futures: Should the Level of Speculation Inform Our Choice of Variables?
}

\author{
Christopher Coyle* Fabian Gogolin $^{\dagger}$ Fearghal Kearney ${ }^{\ddagger}$
}

September 27, 2018

\begin{abstract}
Prior literature provides conflicting evidence about the impact of speculation on gold futures returns, volatility, and the relationship between market fundamentals and prices. In this paper, we exploit trade volume information to determine the most appropriate family of factors to adopt when modelling gold futures. Using the Disaggregated Commitment of Traders report, we find that extreme levels of speculation are informative in that they signify a shift in the relative modelling accuracy of macroeconomic and latent factors. A simple composite prediction framework, incorporating the changing level of speculation, empirically demonstrates the uncovered phenomenon and offers improved predictive accuracy for gold futures prices. Furthermore, our findings are shown to be robust to alternative latent and macroeconomic model specifications.
\end{abstract}

\section{Introduction}

The role played by speculation as a driver in financial markets has received widespread attention in the last decade, most notably in the debate surrounding

\footnotetext{
*Queen's Management School, Queen's University Belfast, BT9 5EE, UK. E-mail address: C.coyle@qub.ac.uk.

†Queen's Management School, Queen's University Belfast, BT9 5EE, UK. E-mail address: F.gogolin@qub.ac.uk.

${ }^{\ddagger}$ Corresponding author at: Queen’s Management School, Queen’s University Belfast, BT9 5EE, UK. Tel.: +44 (0) 289097 4795; E-mail address: F.kearney@qub.ac.uk.
} 
commodity price spikes, which has led to calls for increased regulation of speculative activity. ${ }^{1}$ This debate is closely related to the recent financialization of commodity markets following the discovery of a negative correlation between commodity returns and stock returns (Greer, 2000; Gorton and Rouwenhorst, 2006; Erb and Harvey, 2006; Tang and Xiong, 2012). A popular view, is that increased financialization has enabled commodity markets to become a new 'investment class', allowing speculation to become a major price determinant, and resulting in increased volatility that cannot be explained by changes in economic fundamentals. ${ }^{2}$ Although there is much opposition to this view, a divorce of fundamentals from markets could have important implications for our ability to accurately explain commodity prices, with knock-on effects for producers, consumers and investors.

Gold, which has experienced a price increase of over 100\% during our 20062018 sample period but has shown a relative lack of volatility, has received little attention in relation to the impact of speculation. This is despite its centuriesold position as an important investment asset negatively correlated with stock markets. The importance of gold is mirrored in its turnover, with the London Bullion Market Association reporting an average daily gold trading volume in London of US $\$ 26$ bn in 2017 , while the average worldwide daily trading volume is $35 \%$ greater than all of the stocks in the S\&P 500 combined. ${ }^{3}$ Jordan et al. (2017) further show that gold is such an important and integrated component of modern financial markets that it successfully supplements forecasts of G7 stock market indices. Additionally, gold does not suffer from extreme supply swings like energy and agricultural commodities, reducing the opportunity for speculative bubbles (Bertus and Stanhouse, 2001), and making it an interesting comparator to studies on the effects of speculation in these markets.

Since the seminal work of Friedman (1953), which suggests that speculation is stabilising, as profitable speculation must involve buying when the price is low and selling when the price is high, a strand of literature has emerged seeking to extract information about who trades. Early literature highlights positive outcomes asso-

\footnotetext{
${ }^{1}$ The Economist, "Of Mice and Markets", 10 September 2016; The Economist, "Tying the hands of speculators", 19 October 2011; The Economist, "Pure Speculation", 23 June 2008; The Financial Times, "Commodity speculation must be curbed", 25 July 2008.

${ }^{2}$ The Financial Times, "Fundamentals do not matter to new breed of oil speculator", 27 Feb 2018.

${ }^{3}$ http://www.lbma.org.uk/clearing-statistics; https://www.statista.com/statistics/625422/dailytrading-volumes-of-major-financial-assets-worldwide/
} 
ciated with speculators who by definition are not constrained in terms of how they trade. For instance, De Long et al. (1990) and Rahi and Zigrand (2009) show that the presence of such rational arbitrageurs eliminates pricing distortions. Brunetti et al. (2016) find no evidence that speculators destabilize financial markets and find instead that speculative trading reduces volatility in oil, natural gas and corn futures. Knittel and Pindyck (2016) show that speculation had little, if any, effect on prices and volatility in oil markets between 1999 and 2012. Kim (2015) finds that across a range of commodity futures including gold, speculation is not related to large price changes. Additionally, for energy and agricultural commodity futures, Kim (2015) finds that speculation either has no effect, or, contributes to lower spot price volatility, and improved efficiency and liquidity.

There has been some empirical support for the view that high and volatile commodity prices are, in part, a result of speculation. Singleton (2014) argues that speculative activity associated with informational frictions may result in price booms and busts. Examining the price impact of speculation in precious metals futures between 2006 and 2013, Bosch and Pradkhan (2015) find no short-term impact on returns or return volatility, but they do not rule out the possibility of a long-term destabilising effect of speculation. The potential effects of speculative trading on prices extends to the theory that periods of speculation can drive prices away from fundamental values. Shleifer and Summers (1990) show that prices can be affected by investors' actions that are not fully justified by fundamental news. Webb (2012) also outlines that there are price changes in speculative markets that are entirely trading induced, and cannot be explained by new fundamental information. Specifically in gold futures markets, Smales (2014) demonstrates that the relationship between news and returns is affected by levels of speculation, while Bertus and Stanhouse (2001) show that speculation can cause rational deviation of prices from fundamentals in gold, as the expectation of price changes results in actual price changes irrespective of underlying fundamental drivers.

This suggests that speculative trading can introduce new dynamics into markets that influence the relationship between fundamental variables and prices. Which, whether stabilising or destabilising, may have important implications for our ability to accurately model prices. Therefore, in this paper, we examine whether the level of speculation affects the ability of fundamental macroeconomic factors to explain prices in the gold futures market from 2006-2018. Going beyond 
the independent use of macroeconomic drivers to characterise gold futures prices, we test both observable fundamental macroeconomic factors and unconstrained latent principal component factors. Empirically, we show that fundamental factors are not capable, relative to latent factors, of capturing the additional dynamics attributable to an elevated level of speculative activity in gold futures markets. This is further exhibited through a composite prediction framework that uses speculation to inform factor inclusion, resulting in significantly improved modelling precision.

These findings contribute to the debate examining the effect of speculation on gold markets (Kim, 2015; Bosch and Pradkhan, 2015; Andreasson et al., 2016), and specifically, support the findings of Smales (2014) and Bertus and Stanhouse (2001) that speculation can drive prices in the gold market away from their fundamentals. Our findings also add to the literature that attempts to go beyond fundamental macroeconomic factors and use Principal Component Analysis (PCA) to model prices in commodity and gold markets (Ulrich, 2000; Daskalaki et al., 2014; Gogolin and Kearney, 2016). Using an aggregated measure of speculation calculated from the Commitment of Traders Report, Gogolin and Kearney (2016) show that PCA does a better job than macroeconomic factors in explaining price movements during high levels of speculation in oil futures. However, Fattouh et al. (2013) highlight potential problems when using aggregated data to study the question of speculation. Our findings add to that of Gogolin and Kearney (2016), by suggesting that speculation affects the informational content of fundamental variables even in the inherently less speculative gold market (Bertus and Stanhouse, 2001), and when using the more granular Disaggregated Commitment of Traders Report when calculating levels of speculation. Interestingly, we also find that increased speculation correlates with decreased price volatility, supporting the findings of Brunetti et al. (2016) and Kim (2015) for energy and agricultural markets, but contrary to the suggestions of Bosch and Pradkhan (2015) for precious metals and the assumptions made by Gogolin and Kearney (2016) for oil futures. These results indicate that high levels of speculation can lead to prices that are more stable than fundamentals are able to fully explain, and under these conditions, PCA does a better job at accounting for these added dynamics.

The paper proceeds as follows. Section 2 explains our methodology and data sources. Section 3 presents and discusses our empirical results. In Section 4, we 
test the sensitivity of our results to alternative specifications. Section 5 provides a brief summary and suggestions for further research.

\section{Methodology}

This paper seeks to compare the modelling accuracy of two distinct families of factors in gold futures markets. To this end, we begin with the approach of Gogolin and Kearney (2016) by constructing structurally similar integrated models comprised of principal component and macroeconomic factors. Our methodology extends that of Gogolin and Kearney (2016), who consider crude oil contracts. This includes, considering alternative macroeconomic and principal component specifications; using the more granular Disaggregated Commitment of Traders Report when calculating levels of speculation; and by extracting data only on days that the Disaggregated Commitment of Traders Report is released, to avoid assuming constant speculation across the week. Firstly, we specify the following statistical model with three principal components:

$$
G C_{t}^{\tau}=\alpha+\beta_{1} F 1_{t-1}+\beta_{2} F 2_{t-1}+\beta_{3} F 3_{t-1}+\varepsilon_{t},
$$

with $F 1, F 2$ and $F 3$ denoting the first, second and third principal components calculated from the gold futures prices, and $G C$ denoting the log return of continuous gold futures (GC) with maturity $\tau$ at time $t$. We hereafter refer to this model as $P C$. PCA models do not require à priori specification of factors, enabling the detection of any factor that may be used as a candidate for pricing commodity returns (Daskalaki et al., 2014). We use three principal components here in line with Ulrich (2000). In Ulrich (2000) the modes of fluctuations for the gold futures price curve are captured using principal component decomposition with three components retained. Ulrich (2000) states that the first is associated with gold futures price level, the second mode is associated with the slope of the futures price curve, and the third is associated with changes in its curvature. However, the three principal components will capture any three factors that explain prices most accurately. In Section 4 we also test for robustness to alternative numbers of retained components, i.e., retaining one and two principal components. Further details of the PCA implementation are provided in Section 2.1.

Secondly, based on commodity futures fundamental factors outlined in Andre- 
asson et al. (2016), a similar linear model for gold futures returns is constructed:

$$
G C_{t}^{\tau}=\alpha+\beta_{1} S P 500_{t-1}+\beta_{2} V I X_{t-1}+\beta_{3} U S D_{t-1}+\beta_{4} E_{c P o l} P_{t-1}+\varepsilon_{t},
$$

with SP500 denoting S\&P500 log return, VIX denoting VIX volatility index log change, USD denoting the trade weighted US dollar index change; and EcPol denoting US economic policy uncertainty index log change. We hereafter refer to this model as Macro. This paper aims to compare the families of factors in differing speculative environments, not to prescribe specific fundamental factors that drive the price of gold. Andreasson et al. (2016) argue that the above model applies across all commodity futures, so we adopt these general fundamental factors. However, in Section 4 we also consider an alternative macro model, including additional gold specific factors identified by O'Connor et al. (2015).

Changes in speculative activity are gauged through the adoption of the Working's T (1960) ratio, expressed as follows:

$$
\begin{aligned}
& W=1+\frac{S S}{H L+H S} \quad \text { if } H S \geq H L \\
& W=1+\frac{S L}{H L+H S} \quad \text { if } H S<H L
\end{aligned}
$$

where $S S(S L)$ is the open interest of speculators holding net short (long) positions, and $H S(H L)$ is the open interest of hedgers holding net short (long) positions. The motivating rationale for the ratio is that speculators are necessary only insofar as they represent a counterparty for hedgers. The Working's T (1960) ratio should be interpreted as a proxy, and not a precise measure of speculative activity, due to non-reportable positions and possible trader misclassification, i.e., commercials engaging in speculative activity. Values in the Working's T (1960) 5090th percentile range are used to indicate increasingly speculative environments.

Finally, we produce a combined prediction model driven by the level of speculation, aligning with Bates and Granger (1969) who conclude that when more than one predictive model is available, it is rarely (if ever) optimal to use a single 
prediction in isolation. It is represented as:

$$
\begin{gathered}
G C_{t}^{\tau}=\gamma_{t}^{\text {Macro }} \text { Macro } \hat{t}_{t}^{\tau}+\gamma_{t}^{P C} P \hat{C}_{t}^{\tau}+\varepsilon_{t}, \\
\gamma_{t}^{\text {Macro }}\left\{\begin{array}{lll}
1 & \text { if } & W_{t}<W_{\varrho} \\
0 & \text { if } & W_{t} \geq W_{\varrho}
\end{array}\right. \\
\gamma_{t}^{P C}\left\{\begin{array}{lll}
1 & \text { if } & W_{t} \geq W_{\varrho} \\
0 & \text { if } & W_{t}<W_{\varrho}
\end{array}\right.
\end{gathered}
$$

with $W_{t}$ denoting the Working's $\mathrm{T}$ for day $t$, and $W_{\varrho}$ denoting the chosen percentile Working's T cutoff value. We hereafter refer to this model as Combo.

We now outline our data sources. Gold GC1-GC4 prices are from the CME Group and obtained through the Quandl platform. These generic futures contracts are rolled on their last trading day and prices are not adjusted. The fundamental factors utilised are daily VIX quotes from the CBOE, S\&P500 values retrieved from Yahoo! Finance, and the Trade Weighted US Dollar Index and US Economic Policy Uncertainty Index, from FRED. Furthermore, to calculate the Working's $\mathrm{T}$ ratio, the Futures Only Disaggregated Commitment of Traders (DCoT) report is retrieved from the CFTC. When adopting the report we specify the category Producers, Merchants, Processors and Users (PMPU) as the hedgers and the category Money Manager as the speculators. This removes the swap dealers, which are not traditional hedgers in this sense, as they are likely to be gold mining companies or other firms directly related to dealing with the commodity gold. For our later robustness checks, we obtain the US Treasury 1 Year Zero-Coupon yield from FRED, and the generic continuous 2nd month WTI oil price (CL2) from the CME Group. As the Commitment of Traders report is released on a weekly basis, previous studies have assumed that the Working's T speculation signal spans the week-long period. However, we instead retain only days corresponding to weekly DCoT report releases, avoiding the need to make such an assumption. As the DCoT report is released each Turesday, only data from these days are retained. Furthermore, the use of weekly data frequency minimises the impact of volatility clustering, heteroscedasticity and excess kurtosis that is often associated with daily data. This leads to a sample that is studied at a weekly frequency from June 2006 to April 2018. 


\subsection{Principal Component Analysis}

PCA is based on the concept of utilising a smaller set of unobservable latent statistical factors to explain the systematic behaviour of a larger set of variables that we observe. Mechanically, the PCA procedure transforms $p$ correlated variables to an orthogonal system of variables with the aim of replicating the original variance-covariance correlation matrix as closely as possible. The variancecovariance structure that we wish to capture in this paper is the relationship that links together gold futures contract prices of varying maturities. As in Chantziara and Skiadopoulos (2008), we apply the PCA approach to the daily first differences in commodity futures price term structure. To improve methodological clarity we adopt their notational conventions below also.

With time being denoted as $t=1, \ldots, T$ and $p$ representing the number of variables, PCA proceeds by constructing a small number of statistical components that are linear combinations of the $(T x 1)$ dimensioned $\boldsymbol{x}$ vectors and are orthogonal to one another. As stated above the goal for these components is to explain as much of the original correlation or variance/covariance matrix as possible. The first statistical variable, or first principal component (PC), is constructed following this maximisation principal. The second PC then seeks to explain as much of the remaining variance as possible but it has the additional constraint that it must be uncorrelated to the first. This continues for $p$ principal components. Representing this process in matrix notation, we say that:

$$
Z=X \boldsymbol{A}
$$

with $\boldsymbol{X}$ representing a Txp dimension matrix of PCs, and $\boldsymbol{A}$ a $p x p$ dimension matrix of corresponding PC loadings. Implementing the constraint on our maximisation leads to:

$$
\left(\boldsymbol{X}^{\prime} \boldsymbol{X}-I l\right) \boldsymbol{A}=0
$$

with $l_{i}$ denoting the Lagrange multipliers and $I$ indicating a $p x p$ dimension identity matrix. From this, it can be seen that the PCA process essentially involves calculating eigenvalues $\left(l_{i}\right)$ and eignvectors $(\boldsymbol{A})$ of the variance-covariance matrix 
$\boldsymbol{S}=\boldsymbol{X}^{\prime} \boldsymbol{X}$. Moreover, the $i$ th eigenvalue corresponds to the variance of the $i$ th $\mathrm{PC}$, and the cumulative variance of the $\boldsymbol{X}$ variables corresponds to the cumulative variance of the PCs uncovered.

What is generally observed with empirical data is that a small number of PCs can explain a large proportion of variance in the original data. In such a situation the remaining components are generally ignored, leading to a great reduction in the dimensionality of the original data. In matrix notation. If we retain $r<p$ PCs, then,

$$
\boldsymbol{X}=\boldsymbol{Z}_{(r)} \boldsymbol{A}_{(r)}^{\prime}+\varepsilon_{(r)}
$$

with $\varepsilon_{(r)}$ being a $(T x p)$ matrix of residuals and $\boldsymbol{X}, \boldsymbol{Z}$ and $\boldsymbol{A}$, now having $r$ columns.

There are a number of different approaches to deciding the size of $r$. The most common is the use of a threshold of total variance that must be explained, for instance, retain PCs that account for $90 \%$ of total variance. Another common approach is to stop increasing $r$, once a component contributes less than $5 \%$ to total explained variance. A more formal but less commonly employed approach is to make use of statistical frameworks, including Horn (1965) and Glorfied (1995)'s parallel analysis test approach, as we also consider. As stated by Chantziara and Skiadopoulos (2008) the ultimate decision should be made using a combination of factors, including the use of formal and informal rules and the interpretation of the uncovered components.

This general principal component modelling approach is shown by Stock and Watson (2002) to provide consistent estimators of the inherent latent factors, which can be deployed effectively in a linear regression setting. Furthermore, the forecasts that arise from the use of PCA in a regression setting such as this, converge to the forecasts from a specification where the latent factors are in fact known. Despite these principal component factors not being specified with a clear economic interpretation a priori, they are said to encompass all information about the unknown factors that drive the future term structure process. For these reasons, we use the $r$ principal components as factors to model and forecast the dynamics of the gold futures price curve for various contract maturities in a parsimonious manner, as per the specification in $P C$ model described in Section 2. Furthermore, given the imprecision in chosing the "correct" number of principal component fac- 
Table 1: PC Regression Estimates

\begin{tabular}{lcccc}
\hline \hline & \multicolumn{4}{c}{ Dependent variable: } \\
\cline { 2 - 5 } & \multicolumn{4}{c}{ Gold Contracts } \\
& GC1 & GC2 & GC3 & GC4 \\
\hline PC1 & $0.570^{* * *}$ & $0.430^{* * *}$ & $0.446^{* * *}$ & $0.540^{* * *}$ \\
& $(0.001)$ & $(0.001)$ & $(0.001)$ & $(0.001)$ \\
PC2 & $-0.404^{* * *}$ & $0.541^{* * *}$ & $0.566^{* * *}$ & $-0.473^{* * *}$ \\
& $(0.004)$ & $(0.005)$ & $(0.005)$ & $(0.004)$ \\
PC3 & $0.572^{* * *}$ & $-0.463^{* * *}$ & $0.387^{* * *}$ & $-0.555^{* * *}$ \\
& $(0.007)$ & $(0.009)$ & $(0.010)$ & $(0.007)$ \\
Constant & $-0.001^{* * *}$ & $-0.0002^{* * *}$ & $-0.0004^{* * *}$ & $-0.001^{* * *}$ \\
& $(0.00003)$ & $(0.00003)$ & $(0.00003)$ & $(0.00003)$ \\
\hline Observations & 621 & 621 & 621 & 621 \\
$\mathrm{R}^{2}$ & 0.998 & 0.995 & 0.995 & 0.998 \\
Adjusted $\mathrm{R}^{2}$ & 0.998 & 0.995 & 0.995 & 0.998 \\
\hline \hline
\end{tabular}

This table presents OLS regression estimation results when fitting the factors from the PC model to each maturity gold futures (GC1 - GC4) contemporaneously over the June 2006 to April 2018 period at a weekly frequency. In the table * denotes significance at the $10 \%$ level, $* *$ denotes significance at the $5 \%$ level, and $* * *$ denotes significance at the $1 \%$ level.

tors, as outline above, we show that our findings are robust to alternative choices of $r$ in Section 4.

\section{Empirical Results}

We include fitted regression results using the variables from the PC model as independent factors in Table 1 . The average adjusted $\mathrm{R}^{2}$ value across the gold futures contracts stands at $99.65 \%$, indicating that latent factors extracted to explain the maximum levels of variation in the data, can also comprehensively explain gold futures prices when cast in a contemporaneous linear regression setting. Table 2 shows the linear regression results using the fundamental variables from the Macro model, with its a priori specified macroeconomic factors leading to an adjusted $\mathrm{R}^{2}$ value in the $12.6 \%$ to $16.4 \%$ range. More importantly, the accuracy of each of the families of factors to predict future observations is assessed for the 2006-2018 period with the associated Root Mean Squared Errors (RMSE) and Mean Absolute Errors (MAE) presented in Table 3. Directly comparing the 
Table 2: Macro Regression Estimates

\begin{tabular}{lcccc}
\hline \hline & \multicolumn{4}{c}{ Dependent variable: } \\
\cline { 2 - 5 } & GC1 & GC2 & GC3 & GC4 \\
\hline SP500 & $-0.188^{* * *}$ & $-0.140^{* * *}$ & $-0.143^{* * *}$ & $-0.176^{* * *}$ \\
& $(0.063)$ & $(0.049)$ & $(0.051)$ & $(0.060)$ \\
VIX & $-0.018^{*}$ & -0.007 & -0.009 & $-0.016^{*}$ \\
& $(0.010)$ & $(0.008)$ & $(0.008)$ & $(0.009)$ \\
USD & $-1.185^{* * *}$ & $-1.065^{* * *}$ & $-1.059^{* * *}$ & $-1.195^{* * *}$ \\
& $(0.125)$ & $(0.096)$ & $(0.100)$ & $(0.118)$ \\
Eco Policy & -0.0003 & 0.0002 & -0.0004 & 0.0004 \\
& $(0.001)$ & $(0.001)$ & $(0.001)$ & $(0.001)$ \\
Constant & -0.001 & -0.0001 & -0.0002 & -0.001 \\
& $(0.001)$ & $(0.0004)$ & $(0.0004)$ & $(0.001)$ \\
\hline Observations & 621 & 621 & 621 & 621 \\
$\mathrm{R}^{2}$ & 0.131 & 0.169 & 0.158 & 0.143 \\
Adjusted R $\mathrm{R}^{2}$ & 0.126 & 0.164 & 0.152 & 0.138 \\
\hline \hline
\end{tabular}

This table presents OLS regression estimation results when fitting the factors from the Macro model to each maturity gold futures (GC1 - GC4) contemporaneously over the June 2006 to April 2018 period at a weekly frequency. In the table $*$ denotes significance at the $10 \%$ level, $* *$ denotes significance at the $5 \%$ level, and $* * *$ denotes significance at the $1 \%$ level.

Table 3: Performance Metrics

\begin{tabular}{lcccc}
\hline & GC1 & GC2 & GC3 & GC4 \\
\hline PC RMSE & 0.0144 & 0.0112 & 0.0116 & 0.0138 \\
PC MAE & 0.0091 & 0.0083 & 0.0084 & 0.0088 \\
Macro RMSE & 0.0143 & 0.0111 & 0.0115 & 0.0137 \\
Macro MAE & 0.0090 & 0.0083 & 0.0084 & 0.0088 \\
RW RMSE & 0.0210 & 0.0160 & 0.0167 & 0.0201 \\
RW MAE & 0.0131 & 0.0117 & 0.0120 & 0.0126 \\
\hline
\end{tabular}

This table presents Root Mean Squared Error (RMSE) and Mean Absolute Error (MAE) loss functions for the PC, Macro and Random Walk (RW) models for each maturity gold futures (GC1 - GC4) over the June 2006 to April 2018 period at a weekly frequency. The results of a two-tailed $t$-test to determine statistically significant differences between

the PC and Macro models performance measures are indicated with asterisks $(*)$. $*$ denotes significance at the $10 \%$

level, ** denotes significance at the $5 \%$ level, and $* * *$ denotes significance at the $1 \%$ level 
Table 4: Speculation Subsample Errors

\begin{tabular}{lrcccc}
\hline Percentile & Working's T & $P C \overline{R M S E}$ & $P C \overline{M A E}$ & Macro $\overline{R M S E}$ & Macro $\overline{M A E}$ \\
\hline \multicolumn{2}{l}{ Least speculative periods } & & & & \\
$50 \%$ & $<1.1167$ & 0.01224 & 0.00944 & 0.01221 & 0.00940 \\
$60 \%$ & $<1.1722$ & 0.01298 & 0.00928 & 0.01291 & 0.00922 \\
$70 \%$ & $<1.2121$ & 0.01365 & 0.00941 & 0.01349 & 0.00932 \\
$80 \%$ & $<1.3338$ & 0.01378 & 0.00931 & 0.01364 & 0.00923 \\
$90 \%$ & $<1.5731$ & 0.01335 & 0.00906 & 0.01323 & 0.00901 \\
& & & & & \\
\multicolumn{1}{l}{ Most speculative periods } & & & & \\
$50 \%$ & $\geq 1.1167$ & 0.01338 & 0.00789 & 0.01321 & 0.00787 \\
$60 \%$ & $\geq 1.1722$ & 0.01259 & 0.00773 & 0.01243 & 0.00775 \\
$70 \%$ & $\geq 1.2121$ & 0.01066 & 0.00692 & 0.01071 & 0.00703 \\
$80 \%$ & $\geq 1.3338$ & 0.00793 & 0.00606 & 0.00808 & 0.00624 \\
$90 \%$ & $\geq 1.5731$ & 0.00633 & 0.00509 & 0.00651 & 0.00528 \\
\hline
\end{tabular}

This table presents $\overline{R M S E}$ and $\overline{M A E}$, the RMSE and MAE loss functions averaged over the GC1-GC4 (gold futures). The loss functions are presented for the PC and Macro factors using subsample periods split according to increasing percentile Working's T (1960) ratio values as given in the Working's T column. Specifically, observations with a calculated Working's $\mathrm{T}$ value greater than or equal to the 50-90th percentile level are labelled "most speculative" with the remaining observations being referred to as "least speculative".

errors, the performance of the PC and Macro factors are very similar. The higher errors associated with the naive Random Walk benchmark is a suggestion that both models achieve a predictive accuracy beyond what would occur by chance alone. The difficulty of beating this Random Walk model when predicting gold prices is highlighted by Hassani et al. (2015). A tractable $t$-test fails to yield any instances of statistically significant differences between PC and Macro factors across the gold futures. The results here can be interpreted as an indication that the predictions that arise from the unconstrained statistical factors we uncover closely mirror those from the fundamental variables that are explicitly identified and incorporated into the Macro model.

We now introduce our measure of speculation to assess if it can inform which variables most accurately determine gold futures returns. We classify days with calculated Working's T index ratios of greater than or equal to the 50th, 60th, 70th, 80th and 90th percentile full sample ratios respectively, as "most speculative", with all the remaining days being classified as "least speculative". As an illustrative example, using the 90 th percentile value, we classify the 62 weekly observations with Working's T ratios of greater than or equal to 1.5731 as the "most speculative" 
Table 5: Composite Model Errors

\begin{tabular}{|c|c|c|c|c|c|}
\hline & Overall & GC1 & GC2 & GC3 & GC4 \\
\hline Combo RMSE & 0.01271 & 0.01429 & 0.01111 & 0.01151 & 0.01365 \\
\hline Combo MAE & 0.00861 & 0.00901 & 0.00828 & 0.00838 & 0.00878 \\
\hline PC RMSE & $0.01282^{* *}$ & $0.01441^{*}$ & 0.01121 & 0.01162 & 0.01376 \\
\hline PC MAE & $0.00866^{*}$ & 0.00906 & 0.00833 & 0.00844 & 0.00882 \\
\hline Macro RMSE & $0.01272^{* * *}$ & 0.01430 & $0.01112^{*}$ & $0.01152^{*}$ & $0.01366^{*}$ \\
\hline Macro MAE & $0.00863^{* * *}$ & 0.00902 & $0.00831^{* *}$ & $0.00841^{*}$ & 0.00880 \\
\hline
\end{tabular}

subsample, with the remaining 558 weekly observations for each generic futures contract, being classified as the "least speculative" sample.

Table 4 presents the calculated performance metrics associated with these speculation informed subsample splits. Initially turning our attention to the least speculative subsamples, we observe that for the 80th and 90th percentile least speculative Working's T splits, the Macro factors achieve slightly lower errors than the PC factors. In contrast, the errors associated with the most speculative $10 \%$ subsample period is lower for the PC model than the Macro model with RMSE values of 0.00633 vs. 0.00651 . The inference here is that during periods characterised by increased levels of speculator participation it is advantageous to model gold futures using latent factors, with Macro factors most accurately capturing prices during the least speculative periods.

As a means of further examining this phenomenon we construct a simple composite prediction model (Combo model) comprised of the PC prediction for days associated with calculated Working's T ratios equal to or above the 90 th percentile figure, and the Macro model prediction for each of the other days in the sample. Table 5 presents the RMSE and MAE performance metrics for each of the models. Across the full futures curve the Combo model significantly outperforms both the PC and Macro models using the MAE performance measure. We find that switching from Macro to latent factors during the most speculative periods results in a large number of instances of significantly improved predictions, versus employing either model in isolation. 
Figure 1 shows the Working's T ratio and the gold price across our sample. This figure suggest that periods of greater speculative participation corresponds to more stable gold prices. In order to investigate whether this is the case, we construct a measure of realized volatility as in Brunetti et al. (2016), where the realized volatility in month $t$ is the sum of squared returns within period $t$ :

$$
R V_{t}=\sum_{i=1}^{t}\left(r_{i}\right)^{2}
$$

Our measure of realized volatility of gold prices is also graphed in Figure 1. The correlation between our monthly measure of realized volatility and the monthly average of our weekly measure of Working's $\mathrm{T}$ is -0.165 , again suggesting that periods of increased speculation correspond to lower gold price volatility in our sample.

\subsection{Discussion of Results}

Our results suggest that during periods of elevated levels of speculative activity, the ability of macroeconomic factors to accurately explain changes in gold futures prices weakens, and latent principal component factors do a better job of accounting for the added dynamics introduced by high levels of speculation. As a result, a composite prediction framework that switches from macroeconomic to latent principal component variables in times of greater speculator participation is a more accurate predictor of gold futures prices. Additionally, our findings suggest that increased speculation correlates with decreased price volatility. This supports the findings of Brunetti et al. (2016) and Kim (2015) for energy and agricultural markets, but is in contrast to the suggestion that speculation has a potentially destabilizing effect for precious metals (Bosch and Pradkhan, 2015). Together, these results suggest that high levels of speculative trading corresponds to prices that are more stable than fundamentals are able to fully explain, in contrast to the assumption made by Gogolin and Kearney (2016) for oil futures.

These results raise the interesting question: What are the dynamics added by elevated levels of speculation that appear to push prices away from what fundamentals would predict? More specifically, why do prices appear to be more stable during periods of relatively high levels of speculation? There could be a number of explanations for this finding. Firstly, this finding could support the traditional view that speculators reduce volatility by trading counter cyclically; dampening 

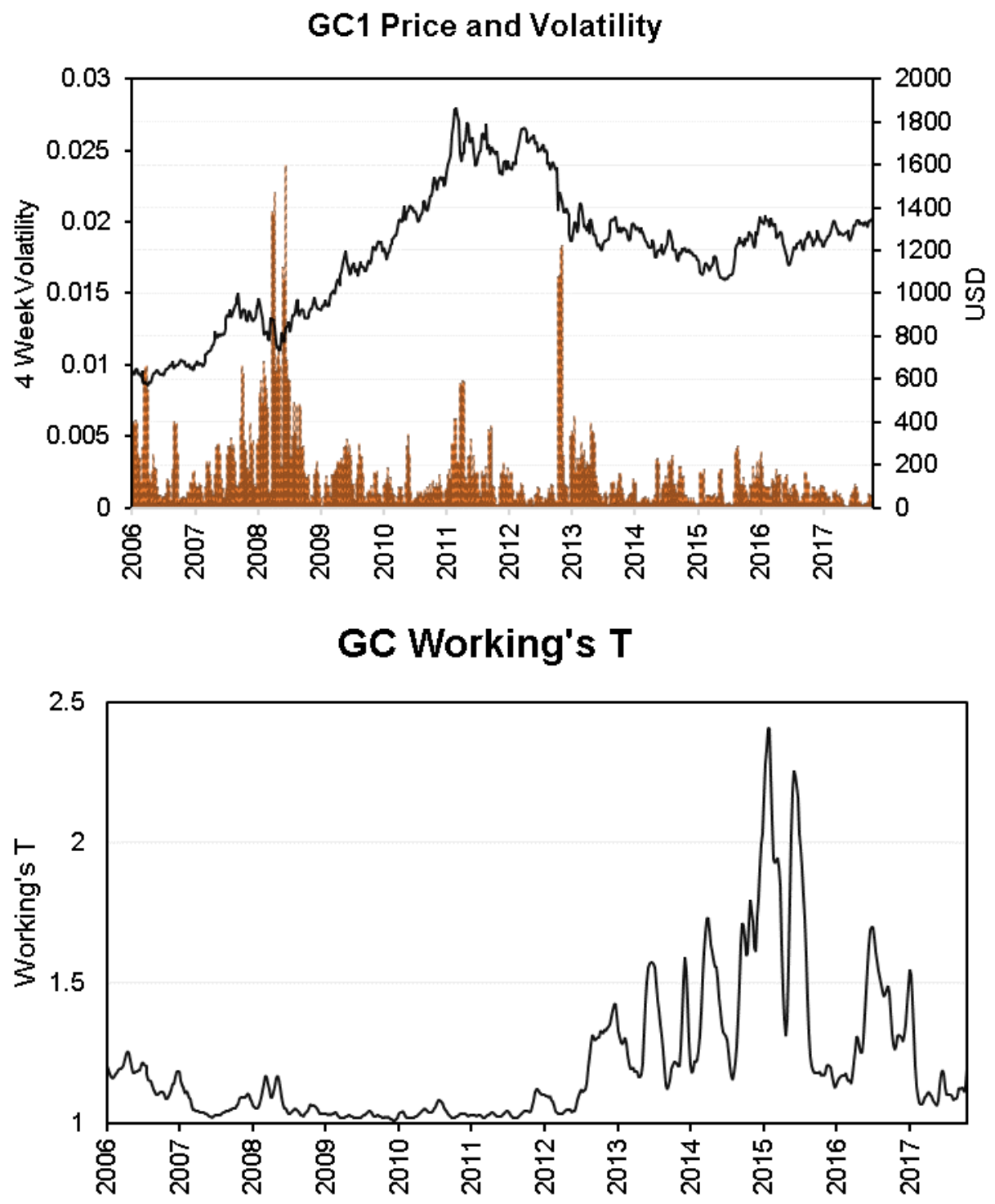

This figure presents in the upper panel a line plot of the GC1 gold price evolution over the June 2006 to April 2018 period, along with its associated 4 week realized volatility measure. In the lower panel, the figure presents a plot of the level of speculator participation as measured by the Working's T index value, again over the June 2006 to April 2018 period.

Figure 1: Gold Price and Level of Speculation 
Table 6: PC Variance

\begin{tabular}{llll}
\hline & PC1 & PC2 & PC3 \\
\hline Standard deviation & 0.025 & 0.007 & 0.004 \\
Proportion of Variance & 0.902 & 0.076 & 0.019 \\
Cumulative Proportion & 0.902 & 0.978 & 0.997 \\
\hline results of the principal component decomposition for $F 1_{t-1}, F 2_{t-1}$, and & $F 3_{t-1}$ for GC1-GC4 \\
(gold futures) over the June 2006 to April 2018 period.
\end{tabular}

This table presents the results of the principal component decomposition for $F 1_{t-1}, F 2_{t-1}$, and $F 3_{t-1}$ for GC1-GC4
(gold futures) over the June 2006 to April 2018 period.

rather than accentuating price increases or decreases (Friedman, 1953). Prices may also be affected by elevated levels of speculative trading due to its associated impact on market microstructure. As a result, price changes that cannot be fully explained by fundamentals may be trading induced (Webb 2012). Kim (2015) finds some evidence that speculative trading in the futures market does have a positive effect on commodity market liquidity as measured by the effective spread and corresponds to lower volatility. A further explanation for our result could be that constraints imposed on speculative traders limit their ability to fully react to changes in fundamental news. If news is positive and a speculative trader faces position limits, this may prevent them from adding to their net position, thus reducing the ability to drive prices as high as may be expected. Therefore, position constraints may influence the relationship between news and returns (Smales 2014).

\section{Other Specifications}

In this Section, we test the sensitivity of our result to alternative latent and macroeconomic specifications. Firstly, we deal with the number of principal components retained for the latent factor specification. Up to now, we have retained three principal components; in line with Ulrich (2000) who interpret the components as the parallel level, slope, and curvature of the futures curve. Figure 2 demonstrates how the principal component loadings vary across our gold futures curve, broadly matching Ulrich's (2000) interpretation of level, slope, and curvature. However, other common approaches include Glorfield's (1995) extension of Horn's (1965) technique; and stopping once a component contributes less than $5 \%$ to explained variance. We see in Figure 3 and Table 6 that both one and two 

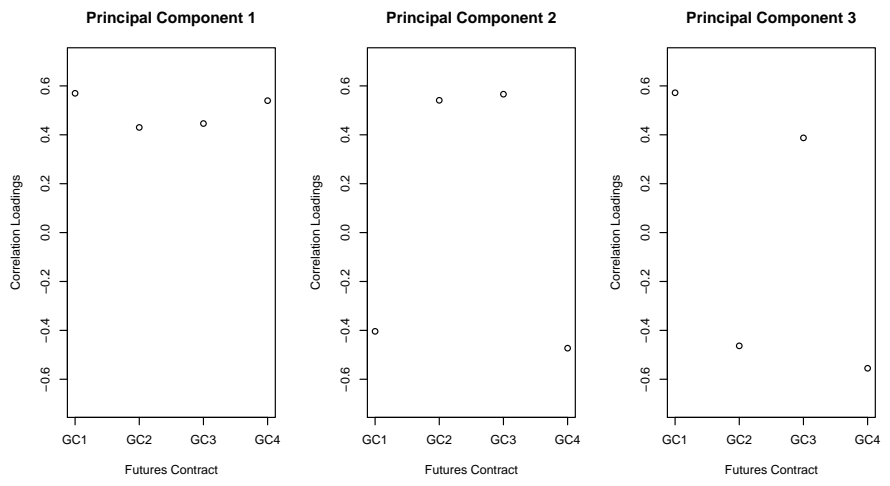

Figure 2: Principal Component Factor Correlations

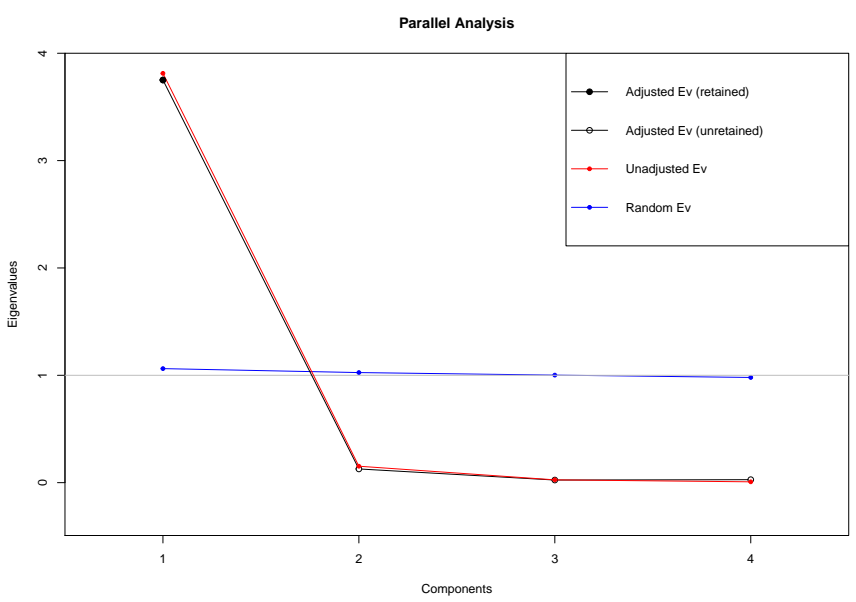

Figure 3: Glorfield (1995) Test Parallel Analysis 
Table 7: Robustness Checks

\begin{tabular}{lccc}
\hline & Alt Macro & 1 PC & 2 PC \\
\hline Combo $\overline{R M S E}$ & 0.01269 & 0.01271 & 0.01271 \\
Combo $\overline{M A E}$ & 0.00860 & 0.00862 & 0.00861 \\
PC $\overline{R M S E}$ & $0.01283^{* * *}$ & $0.01285^{* * *}$ & $0.01283^{* * *}$ \\
PC $\overline{M A E}$ & $0.00866^{* *}$ & $0.00868^{* *}$ & 0.00866 \\
Macro $\overline{R M S E}$ & $0.0127^{* * *}$ & $0.01272^{* *}$ & $0.01272^{* * *}$ \\
Macro $\overline{M A E}$ & $0.00862^{* * *}$ & $0.00863^{* *}$ & $0.00863^{* * *}$ \\
\hline
\end{tabular}

This table presents the predictive accuracy of the PC, Macro, and Combo models using Alt Macro (Alternative Macro specification), $1 \mathrm{PC}$ (Latent model with only 1 principal component, $F 1_{t-1}$, specified), and 2 PC (Latent model with 2 principal components, $F 1_{t-1}$ and $F 2_{t-1}$, specified), specifications. $\overline{R M S E}$ and $\overline{M A E}$, represent the RMSE and MAE loss functions averaged across each of the GC1-GC4 (gold futures) over the June 2006 to April 2018 period at a weekly data frequency. The results of a $t$-test of statistically significantly outperformance for the Combo model over the Macro and $\mathrm{PC}$ models respectively, are indicated with asterisks (*) in the Macro and $\mathrm{PC}$ columns. ${ }^{*}$ denotes significance at the $10 \%$ level, $* *$ denotes significance at the $5 \%$ level, and $* * *$ denotes significance at the $1 \%$ level.

components are retained using these approaches. For this reason, we assess, $1 P C$ :

$$
G C_{t}^{\tau}=\alpha+\beta_{1} F 1_{t-1}+\varepsilon_{t},
$$

and $2 P C$ :

$$
G C_{t}^{\tau}=\alpha+\beta_{1} F 1_{t-1}+\beta_{2} F 2_{t-1}+\varepsilon_{t},
$$

respectively, as alternative latent models. Secondly, we test for sensitivity to our precise fundamental specification for gold futures through the addition of both oil and interest rates factors, as identified by O'Connor et al., (2015). This leads to an alternative macroeconomic model (Alt Macro) that mitigates possible omitted variable bias:

$$
G C_{t}^{\tau}=\alpha+\beta_{1} S P 500_{t-1}+\beta_{2} V I X_{t-1}+\beta_{3} U S D_{t-1}+\beta_{4} E c P o l_{t-1}+\beta_{5} C L_{t-1}+\beta_{6} T_{t-1}+\varepsilon_{t},
$$

where $C L$ represents the generic continuous 2nd month (CL2) WTI oil future log return and $T$ represents the US Treasury 1 Year Zero-Coupon yield. ${ }^{4}$

Table 7 shows us the results (aggregated across the futures curve) of these alternative specifications. Widespread significance is uncovered at the $5 \%$ and $1 \%$ levels for the alternative latent and macro factor specifications. These additional robustness tests support our findings that during periods of elevated levels of

\footnotetext{
${ }^{4}$ Given the inverse link between interest rates and inflation, our alternative model specification could also be interpreted as indirectly incorporating inflation as a factor driving gold futures prices.
} 
speculative activity, the ability of macroeconomic factors to accurately explain changes in gold futures prices weakens, and the proposed speculation informed composite prediction model outperforms in gold futures markets.

\section{Conclusion}

Extant studies provide contradictory evidence about the impact of speculation on futures returns, volatility, and the relationship between market fundamentals and prices. Much of this research has focused on energy and agricultural markets, with very little addressing gold, which, as evidenced by the size of the market is a very important commodity from an investor's perspective. We add to the understanding of the implications of speculation in futures markets, and specifically, the gold futures market, by focusing on the effect of speculation on the predictive accuracy of both fundamental macroeconomic and latent principal component families of factors. We find that during periods characterised by elevated levels of speculative activity, the ability of macroeconomic factors to accurately explain changes in gold futures prices diminishes relative to latent factors.

This paper therefore provides an empirical demonstration that in gold futures markets, high levels of speculation lead to an injection of additional dynamics that cannot be explained by traditional macroeconomic fundamentals. This supports the findings of Bertus and Stanhouse (2001) and Smales (2014), that show speculation can drive prices in the gold market away from their fundamentals. We then demonstrate significant outperformance using a composite prediction framework that switches from macroeconomic to latent principal component variables in times of greater speculator participation. This result is shown to be robust to a number of alternative latent and fundamental model specifications. Additionally, our findings indicate that increased speculation correlates with decreased price volatility, supporting the findings of Brunetti et al. (2016) and Kim (2015) for energy and agricultural markets, but run contrary to the suggestion of Bosch and Pradkhan (2015) that speculation has a potentially destabilizing effect for precious metals. These results suggest that high levels of speculation correspond to prices that are more stable than fundamentals are able to fully explain, in contrast to the assumption made by Gogolin and Kearney (2016) for oil futures. Future research should examine whether this relationship between high levels of speculation, informational content of fundamental macroeconomic variables, and price stability 
is consistent across futures markets. Finally, future research should establish the exact factors that cause the relationship between prices and fundamental variables to break down during elevated periods of speculation. 


\section{References}

Andreasson, P., S. Bekiros, D. K. Nguyen, and G. S. Uddin. 2016. Impact of speculation and economic uncertainty on commodity markets. International Review of Financial Analysis 43:115-127.

Bates, J., and C. Granger. 1969. The combination of forecasts. Journal of the Operational Research Society 20:451-468.

Bertus, M., and B. Stanhouse. 2001. Rational speculative bubbles in the gold futures market: an application of dynamic factor analysis. Journal of Futures Markets 21:79-108.

Bosch, D., and E. Pradkhan. 2015. The impact of speculation on precious metals futures markets. Resources Policy 44:118-134.

Brunetti, C., B. Büyükşahin, and J. H. Harris. 2016. Speculators, prices, and market volatility. Journal of Financial and Quantitative Analysis 51:1545-1574.

Chantziara, T., and G. Skiadopoulos. 2008. Can the dynamics of the term structure of petroleum futures be forecasted? Evidence from major markets. Energy Economics 30:962-985.

Daskalaki, C., A. Kostakis, and G. Skiadopoulos. 2014. Are there common factors in individual commodity futures returns? Journal of Banking \& Finance 40:346363.

De Long, J. B., A. Shleifer, L. H. Summers, and R. J. Waldmann. 1990. Positive feedback investment strategies and destabilizing rational speculation. Journal of Finance 45:379-395.

Erb, C. B., and C. R. Harvey. 2006. The Strategic and Tactical Value of Commodity Futures. Financial Analysts Journal 62:69-97.

Fattouh, B., L. Kilian, and L. Mahadeva. 2013. The role of speculation in oil markets: What have we learned so far? The Energy Journal pp. 7-33.

Friedman, M. 1953. Essays in positive economics. University of Chicago Press. 
Glorfeld, L. W. 1995. An improvement on Horn's parallel analysis methodology for selecting the correct number of factors to retain. Educational and Psychological Measurement 55:377-393.

Gogolin, F., and F. Kearney. 2016. Does speculation impact what factors determine oil futures prices? Economics Letters 144:119-122.

Gorton, G., and K. G. Rouwenhorst. 2006. Facts and Fantasies about Commodity Futures. Financial Analysts Journal 62:47-68.

Greer, R. J. 2000. The nature of commodity index returns. Journal of Alternative Investments 3:45-52.

Hassani, H., E. S. Silva, R. Gupta, and M. K. Segnon. 2015. Forecasting the price of gold. Applied Economics 47:4141-4152.

Horn, J. L. 1965. A rationale and test for the number of factors in factor analysis. Psychometrika 30:179-185.

Jordan, S. J., A. Vivian, and M. E. Wohar. 2018. Stock returns forecasting with metals: sentiment vs. fundamentals. The European Journal of Finance 24:458-477.

Kim, A. 2015. Does futures speculation destabilize commodity markets? Journal of Futures Markets 35:696-714.

Knittel, C. R., and R. S. Pindyck. 2016. The simple economics of commodity price speculation. American Economic Journal: Macroeconomics 8:85-110.

O'Connor, F. A., B. M. Lucey, J. A. Batten, and D. G. Baur. 2015. The financial economics of gold: A survey. International Review of Financial Analysis 41:186205.

Rahi, R., and J.-P. Zigrand. 2009. Strategic financial innovation in segmented markets. Review of Financial Studies 22:2941-2971.

Smales, L. A. 2014. News sentiment in the gold futures market. Journal of Banking E Finance 49:275-286.

Stock, J. H., and M. W. Watson. 2002. Forecasting using principal components from a large number of predictors. Journal of the American Statistical Association 97:1167-1179. 
Tang, K., and W. Xiong. 2012. Index Investment and the Financialization of Commodities. Financial Analysts Journal 68:54-74.

Urich, T. J. 2000. Modes of fluctuation in metal futures prices. Journal of Futures Markets 20:219-241.

Webb, R. I. 2012. Trading and fat tails. Applied Finance Letters 1:2-7.

Working, H., et al. 1960. Speculation on hedging markets. Food Research Institute Studies 1:185-220. 